ARTICLE

\title{
Mind-controlled transgene expression by a wireless-powered optogenetic designer cell implant
}

Marc Folcher ${ }^{1}$, Sabine Oesterle ${ }^{1}$, Katharina Zwicky ${ }^{1}$, Thushara Thekkottil', Julie Heymoz ${ }^{1}$, Muriel Hohmann ${ }^{1}$, Matthias Christen ${ }^{1}$, Marie Daoud El-Baba², Peter Buchmann ${ }^{1} \&$ Martin Fussenegger 1,3

Synthetic devices for traceless remote control of gene expression may provide new treatment opportunities in future gene- and cell-based therapies. Here we report the design of a synthetic mind-controlled gene switch that enables human brain activities and mental states to wirelessly programme the transgene expression in human cells. An electroencephalography (EEG)-based brain-computer interface $(\mathrm{BCl})$ processing mental state-specific brain waves programs an inductively linked wireless-powered optogenetic implant containing designer cells engineered for near-infrared (NIR) light-adjustable expression of the human glycoprotein SEAP (secreted alkaline phosphatase). The synthetic optogenetic signalling pathway interfacing the $\mathrm{BCl}$ with target gene expression consists of an engineered NIR light-activated bacterial diguanylate cyclase (DGCL) producing the orthogonal second messenger cyclic diguanosine monophosphate (c-di-GMP), which triggers the stimulator of interferon genes (STING)-dependent induction of synthetic interferon- $\beta$ promoters. Humans generating different mental states (biofeedback control, concentration, meditation) can differentially control SEAP production of the designer cells in culture and of subcutaneous wirelesspowered optogenetic implants in mice.

\footnotetext{
${ }^{1}$ Department of Biosystems Science and Engineering, ETH Zurich, Mattenstrasse 26, CH-4058 Basel, Switzerland. ${ }^{2}$ Département Génie Biologique, Institut Universitaire de Technologie (IUTA), 74 Boulevard Niels Bohr, F-69622 Villeurbanne, France. ${ }^{3}$ Faculty of Science, University of Basel, Mattenstrasse 26, CH-4058 Basel, Switzerland. Correspondence and requests for materials should be addressed to M.F. (email: fussenegger@bsse.ethz.ch).
} 
M ammalian synthetic biology has significantly advanced the design of gene switches that are responsive to traceless cues such as light ${ }^{1,2}$, gas $^{3}$ and radio waves ${ }^{4}$, complex gene circuits, including oscillators ${ }^{5,6}$, cancer-killing gene classifiers ${ }^{7,8}$ and programmable biocomputers ${ }^{9}$, as well as prosthetic gene networks ${ }^{10}$ that provide treatment strategies for gouty arthritis ${ }^{11}$, diabetes ${ }^{1,12}$ and obesity ${ }^{13}$. Akin to synthetic biology promoting prosthetic gene networks for the treatment of metabolic disorders ${ }^{1,11-13}$, cybernetics advances the design of functional man-machine interfaces in which brain-computer interfaces $(\mathrm{BCI})^{14,15}$ process brain waves to control electromechanical prostheses, such as bionic extremities ${ }^{16}$ and even wheel chairs ${ }^{17}$. The advent of synthetic optogenetic devices that use power-controlled, light-adjustable therapeutic interventions ${ }^{18}$ will enable the merging of synthetic biology with cybernetics to allow brain waves to remotely control the transgene expression and cellular behaviour in a wireless manner.

Optogenetic devices operating in the near-infrared (NIR) spectral range combine high tissue penetration power with negligible phototoxicity ${ }^{19,28}$. The phototrophic bacterium Rhodobacter sphaeroides is able to capture NIR light with the multidomain protein BphG1, which contains an amino-terminal (N-terminal) NIR light sensor and carboxyl-terminal diguanylate cyclase (DGC) domain, as well as phosphodiesterase (PDE) activities, to control the level of the ubiquitous bacterial second messenger cyclic diguanosine monophosphate (c-di-GMP) ${ }^{21}$ and orchestrate the environmental light-triggered transition from motile cells to biofilm-forming communities ${ }^{22}$. Stimulator of interferon genes (STING) ${ }^{23}$ was recently identified as a novel player in the human innate immunity that functions as a cyclic di-nucleotide sensor (cGAMP, c-di-AMP, c-di-GMP) to detect the presence of cytosolic DNA via cyclic-GMP-AMP (cGAMP) synthase (cGAS)-mediated production of cGAMP ${ }^{24}$, as well as second messengers (c-di-AMP, c-di-GMP) released from intracellular pathogens ${ }^{25-27}$. Activated STING specifies the phosphorylation of the interferon-regulatory factor 3 (IRF3) (ref. 28) by tank-binding kinase 1, which results in the nuclear translocation of IRF3, binding to IRF3-specific operators and induction of type I interferon promoters ${ }^{25,28}$. In this study, we rewire BCI-triggered NIR light-based induction of c-di-GMP production by BphG1 variants to c-di-GMP-dependent STINGdriven activation of optimized interferon-responsive promoters to enable mind-controlled transgene expression in mammalian designer cells inside subcutaneous wireless-powered optogenetic implants in mice. Cybernetic control of synthetic gene networks in designer mammalian cells may pave the way for mind-genetic interfaces in future treatment strategies.

\section{Results}

c-di-GMP, an orthogonal second messenger in mammalian cells. The design of the synthetic mammalian optogenetic signalling pathway included the combination of the NIR lightactivated DGCL (pSO4, $\mathrm{P}_{\mathrm{hCMV}}$-DGCL-pA), a PDE-deficient Rhodobacter sphaeroides BphG1 variant that produces the orthogonal second messenger c-di-GMP, and STING (pSTING, $\mathrm{P}_{\mathrm{hCMV}}$-STING-pA) to sense intracellular c-di-GMP levels and manage dose-dependent activation of an engineered interferon- $\beta$ promoter $\mathrm{P}_{\mathrm{IFN}(\mathrm{ACD}+)}$, thereby driving the transcription of a

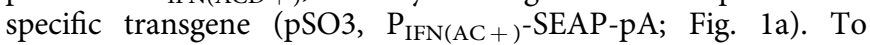
confirm that the prokaryotic DGCLs can produce the bacterial second messenger c-di-GMP in living mammalian cells, we cotransfected HEK-293T cells with DGCA ${ }_{\mathrm{CC} 3285}$, which is feedback inhibited by c-di-GMP (pZKY121, $\mathrm{P}_{\mathrm{Sv} 40}-\mathrm{DGCA}_{\mathrm{CC} 3285}-\mathrm{pA}$ ) and an intracellular fluorescence resonance energy transfer (FRET)based c-di-GMP biosensor (pKZ81, $\mathrm{P}_{\mathrm{Sv} 40}$-mYPet-YcgR-mCyPet;
Fig. 1b). Constitutive expression of the DGCL and the resulting c-di-GMP pool had no negative impact on the viability (Supplementary Fig. 1a) or metabolic capacity (Supplementary Fig. 1b) of the engineered mammalian cells.

Rewiring c-di-GMP to the STING-specific signalling cascade. To demonstrate that c-di-GMP can be functionally rewired for STING-mediated activation of $\mathrm{P}_{\mathrm{hIFNB}}$-driven transgene expression, we co-transfected HEK-293T cells with pZKY121 $\left(\mathrm{P}_{\mathrm{SV} 40}-\mathrm{DGCA}_{\mathrm{CC} 3285}-\mathrm{pA}\right), \quad \mathrm{pSTING}$ ( $\left.\mathrm{P}_{\mathrm{hCMV}}-\mathrm{STING}-\mathrm{pA}\right)$ and pSO1 ( $\left.\mathrm{P}_{\mathrm{hIFN} B}-\mathrm{SEAP}-\mathrm{pA}\right)$ and scored SEAP production after $48 \mathrm{~h}$ (Fig. 1c). When the two different human codon-optimized c-di-GMP-specific phophodiesterases $\mathrm{PDE}_{\text {yahA }}\left(\mathrm{pKZY119}, \mathrm{P}_{\mathrm{SV}_{40}}\right.$ $\mathrm{PDE}_{\mathrm{yahA}}-\mathrm{pA}$ ) and $\mathrm{PDE}_{\mathrm{TBD} 1265}\left(\mathrm{pKZY120}, \mathrm{P}_{\mathrm{SV} 40}-\mathrm{PDE}_{\mathrm{TBD} 1265}-\mathrm{pA}\right)$ were co-transfected into HEK-293T cells co-transfected with pZKY121, pSTING and pSO1, the PDEs reduced the intracellular c-di-GMP inducer pool, resulting in decreased $\mathrm{P}_{\mathrm{hIFNB}}$-driven SEAP expression (Supplementary Fig. 2). The use of $P_{\text {hIFNB }}$ variants with optimized IRF3 operator sites (pSO1, $\mathrm{P}_{\mathrm{hIFNB}}$-SEAP-pA;

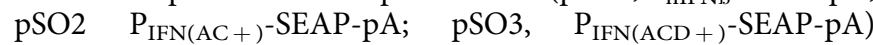
(Supplementary Fig. 3) resulted in an up to 60-fold increase in the response to DGCA $\mathrm{CC}_{\mathrm{C} 285}$-produced c-di-GMP (Fig. 1d).

Control experiments profiling human interferon- $\beta$ (hIFN- $\beta$ ) in the culture supernatant of pZKY121/pSTING/pSO3-cotransfected HEK-293T cells showed no detectable hIFN- $\beta$ levels in the presence of an activated c-di-GMP-based second messenger signalling pathway (Supplementary Fig. 4a). In addition, paracrine hIFN- $\beta$ had no effect on STING-mediated activation of $\mathrm{P}_{\mathrm{IFN}(\mathrm{ACD}+)}$ (Supplementary Fig. 4b). Interestingly, when testing the synthetic second messenger pathway containing the optimal $\mathrm{P}_{\mathrm{IFN}(\mathrm{ACD}+)}$ promoter (pZKY121, $\mathrm{P}_{\mathrm{SV} 40}$-DGCA $\mathrm{CC} 3285_{2}-\mathrm{pA} ; \quad$ pSTING, $\mathrm{P}_{\mathrm{hCMV}}$-STING-pA; pSO3,

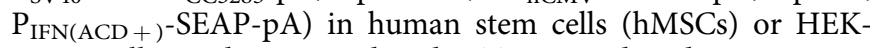
$293 \mathrm{~F}$ cells, c-di-GMP-induced STING-mediated $\mathrm{P}_{\mathrm{IFN}(\mathrm{ACD}+)}$ activation was cell line dependent (Fig. 1e,f). While the ectopic expression of STING significantly increased SEAP expression in hMSCs (Fig. 1e), heterologous STING expression in HEK-293F cells was dispensable, consequently significantly simplifying the synthetic optogenetic device to a two-component configuration (DGCL and $\mathrm{P}_{\mathrm{IFN}(\mathrm{ACD}+\text { ); }}$ Fig. 1f). HEK-293F is a GMP-compliant derivative of the Food and Drug Administration-licensed HEK293 cell line that grows in serum-free suspension cultures, an important asset for the biopharmaceutical manufacturing ${ }^{29}$ and maintenance of cells inside implantable microcontainers.

A NIR light-sensitive transcription control device. To render the synthetic mammalian c-di-GMP pathway responsive to NIR light, we co-transfected HEK-293T cells with DGCL (pSO4, $\mathrm{P}_{\mathrm{hCMV}}$-DGCL-pA), a truncated PDE domain-deficient R. sphaeroides $\mathrm{BphG1}$ variant, $\mathrm{pSO} 3\left(\mathrm{P}_{\left.\mathrm{IFN}(\mathrm{ACD}+)^{-} \mathrm{SEAP}-\mathrm{pA}\right) \text { and }}\right.$ pSTING ( $\mathrm{P}_{\mathrm{hCMV}}$-STING-pA) (Fig. 1a). We then illuminated the engineered cells for different periods of time with an NIR LED panel and recorded the corresponding SEAP expression profiles (Fig. 2a). NIR-light-controlled transgene expression was adjustable (Fig. 2a) and displayed rapid reversible c-di-GMP ON/OFF-response profiles in the range of minutes that were characterized by fast synthesis kinetics (Fig. 2b) and a rapid decrease of intracellular c-di-GMP levels promptly after NIR-light switch-off, possibly due to the presence of numerous endogenous PDEs (Fig. 2b). The synthetic optogenetic signalling pathway was compatible with different mammalian cell lines, including hMSCs (Fig. 2c), as well as HEK-293F (Fig. 2d). To validate the NIR light remote-controlled transgene expression in vivo, we implanted hollow-fibre microcontainers enclosing pSO3-/pSO4-/pSTINGtransgenic HEK-293T cells subcutaneously into mice, 
a

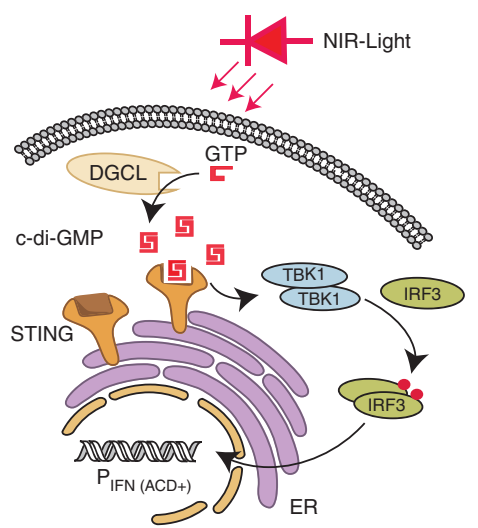

c

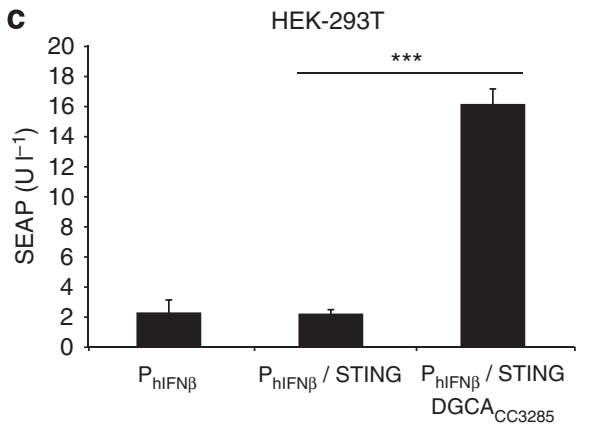

e

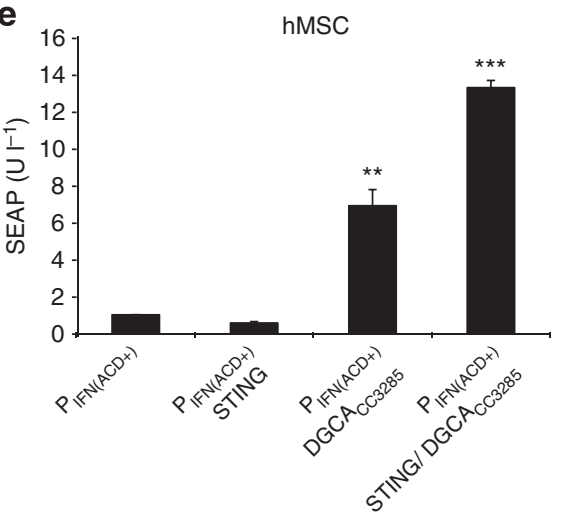

b

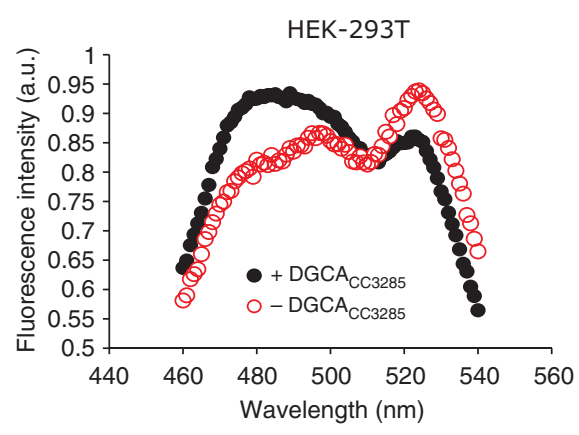

d

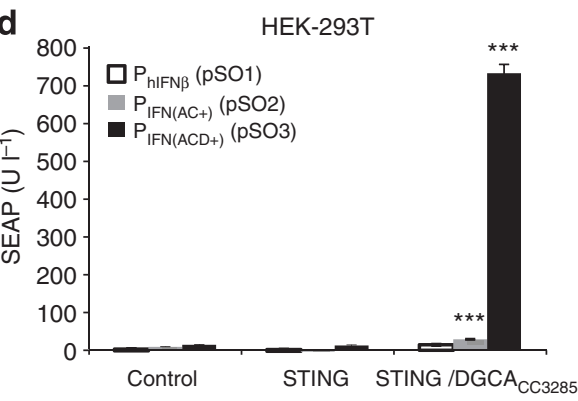

$\mathbf{f}$

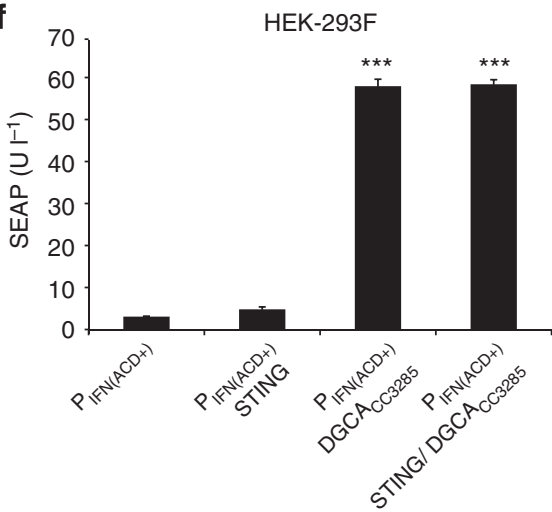

Figure 1 | Synthetic mammalian c-di-GMP-based second messenger pathway. (a) Schematic representation of the synthetic mammalian optogenetic signalling pathway. NIR light activates an engineered light-dependent bacterial phytochrome-associated DGCL, which converts GTP to the orthogonal second messenger cyclic diguanylate monophosphate (c-di-GMP). c-di-GMP binds and activates STING at the endoplasmic reticulum (ER) and specifies tank-binding kinase 1 (TBK1)-mediated phosphorylation of IRF3 (red dots). Phosphorylated IRF3 translocates to the nucleus, binds IRF3-specific operators and induces the optimized type-1 interferon promoters $\left(P_{I F N(A C D+)}\right.$ ). (b) FRET-based detection of c-di-GMP in HEK-293T cells containing the FRET biosensor plasmid pKZY81 ( $P_{S V 40}$-mYPet-YcgR-mCYPet-pA) (co)-transfected with or without the DGCA $A_{c c 3285}$-expression vector pZKY121 $\left(P_{\mathrm{SV} 40}-\mathrm{DGCA}_{\mathrm{CC} 3285}\right.$-pA). After excitation at $425 \mathrm{~nm}$, FRET emission was scanned from 460 to $560 \mathrm{~nm}$ at 2-nm intervals. (c) c-di-GMP-based activation of STING-mediated induction of the hIFN- $\beta$ promoter $\left(P_{\text {hIFNB }}\right)$. A total of $5 \times 10^{5}$ HEK-293T cells were (co)-transfected with different combinations of the constitutive Caulobacter crescentus DGCA (DGCA ${ }_{C C 3285}$ ) expression vector pZKY121 ( $\left.P_{S V 40}-D G C A_{C C 3285}-p A\right)$, the constitutive STING expression vector pSTING ( $P_{h C M v}$-STING-pA) and pSO1 ( $P_{\text {hIFNB }}$-SEAP-pA) to encode the human placental secreted alkaline phosphatase (SEAP) driven by the hIFN- $\beta$ promoter $\left(\mathrm{P}_{\mathrm{hIFNB}}\right)$. SEAP expression was profiled in the culture supernatant after $48 \mathrm{~h}$. HEK-293T cells require ectopic expression of STING to complement

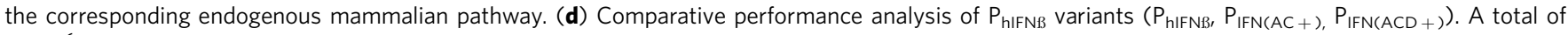
$1 \times 10^{6}$ HEK-293T cells were co-transfected with the DGCA CC $3285^{-}$expression vector pKZY121, pSTING and pSO1 ( hIFNB $\left.-S E A P-p A\right)$, pSO2 $\left(P_{\text {IFN }}(A C+)^{-}\right.$ SEAP-pA) or pSO3 ( $\mathrm{P}_{\mathrm{IFN}(A C D+}+$-SEAP-pA), and SEAP levels were quantified in the culture supernatant after $48 \mathrm{~h}$. Control populations were transfected without pKZY121 or without pKZY121 and pSTING. (e,f) Validation of the synthetic mammalian c-di-GMP-based second messenger pathway in human stem cells (hMSCs; e) and HEK-293T-derived serum-free suspension cultures (HEK-293F; $\mathbf{f}$ ). A total of $5 \times 10^{4}$ hMSCs or HEK-293F cells were

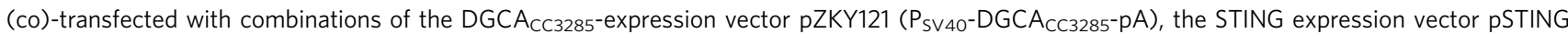
$\left(\mathrm{P}_{\mathrm{hCMV}}-\mathrm{STING}-\mathrm{pA}\right)$ and pSO3 ( $\mathrm{P}_{\mathrm{IFN}(A C D+}$ )-SEAP-pA). SEAP production was assessed in the culture supernatant after $48 \mathrm{~h}$. Data are mean \pm s.d.; statistics by two-tailed $t$-test; $n=6$, triplicate experiments, ${ }^{\star \star} P<0.01,{ }^{\star \star \star} P<0.001$. 

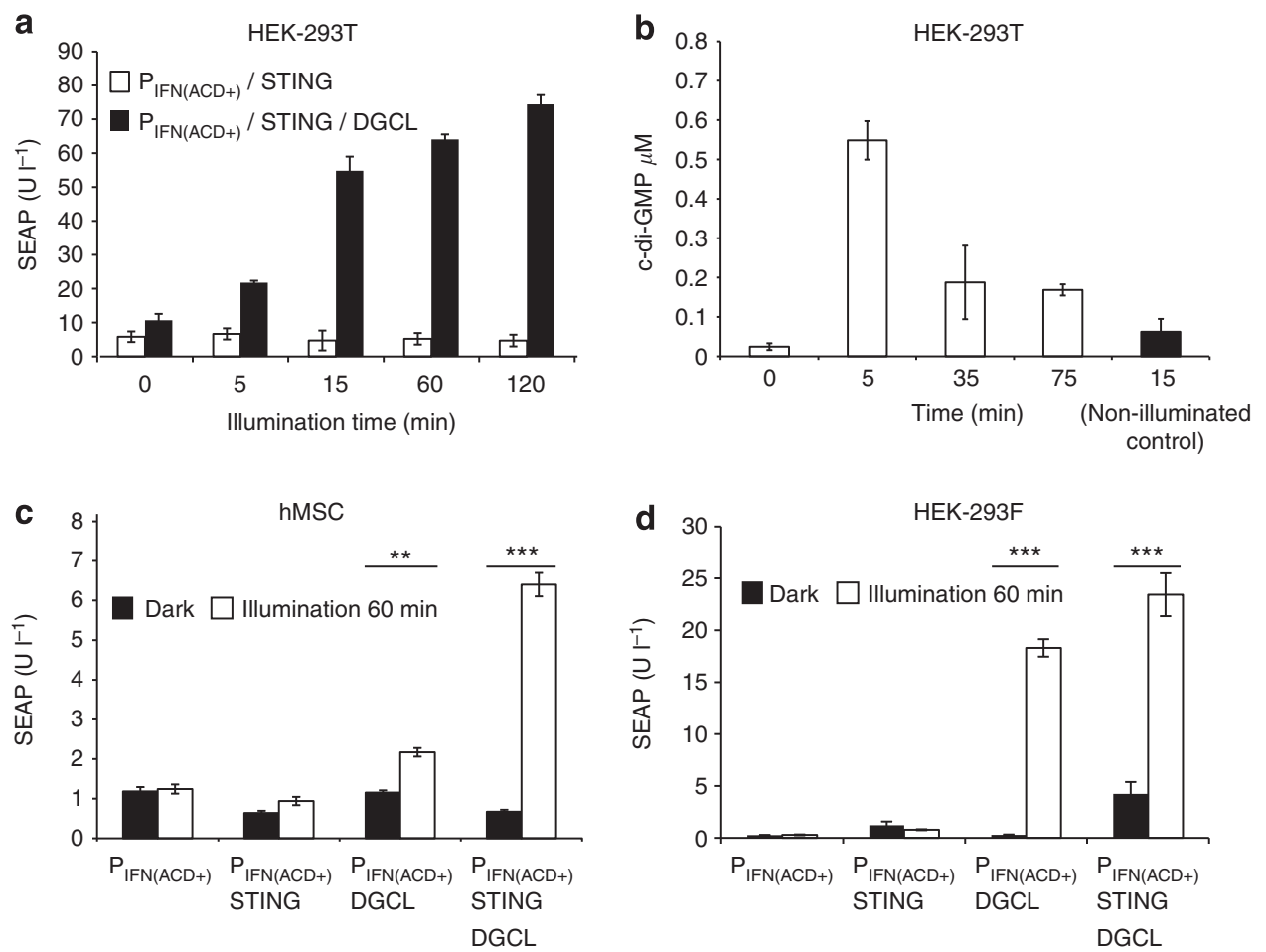

Figure 2 | Design and characterization of the synthetic mammalian optogenetic pathway. (a) A total of $5 \times 10^{4} \mathrm{HEK}-293 \mathrm{~T}$ cells were co-transfected with pSO4 ( $\left.P_{h C M V}-D G C L-p A\right)$, pSTING ( $\left.P_{h C M V}-S T I N G-p A\right)$ and pSO3 ( $P_{\text {IFN }(A C D+)}$-SEAP-pA) and illuminated with NIR light (700 nm) for different periods of time before profiling SEAP in the culture supernatant after $24 \mathrm{~h}$. (b) Quantification of NIR light-induced c-di-GMP in HEK-293T cells. A total of $5 \times 10^{4}$ HEK-293T cells were transfected with pSO4 and illuminated for $15 \mathrm{~min}$ with NIR light $(700 \mathrm{~nm})$. Intracellular c-di-GMP levels were then profiled for different periods of time. Non-illuminated cell populations were used as a negative control. (c,d) Validation of the synthetic mammalian optogenetic pathway in human stem cells (hMSCs; c) and HEK-293T-derived serum-free suspension cultures (HEK-293F; d). A total of $5 \times 10^{4}$ hMSCs (c) or HEK-293F

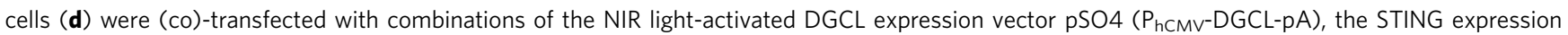
vector pSTING ( $P_{h C M v}$-STING-pA) and pSO3 ( $P_{\text {IFN }(A C D+}$ )-SEAP-pA) to encode the human placental SEAP driven by the engineered hIFN- $\beta$ promoter

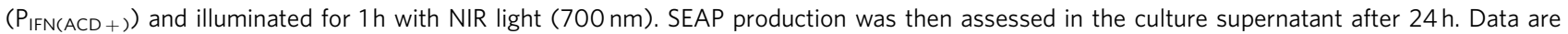
mean \pm s.d.; statistics by two-tailed $t$-test; $n=6$, triplicate experiments, ${ }^{\star \star} P<0.01,{ }^{\star \star \star} P<0.001$.

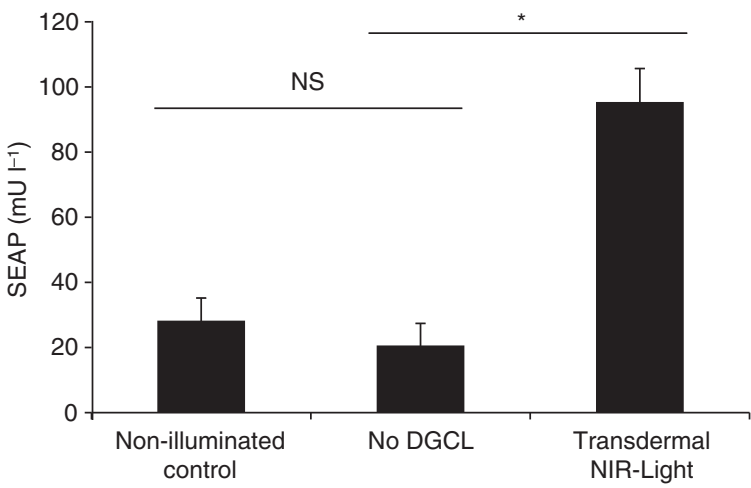

Figure 3 | Percutaneous control of NIR light-inducible transgene expression in mice. Hollow-fibre implants containing $5 \times 10^{4} \mathrm{HEK}-293 \mathrm{~T}$ cells transgenic for pSO4 ( $P_{h C M V}$-DGCL-pA), pSTING ( $P_{h C M V}$-STING-pA) and $\mathrm{pSO} 3\left(\mathrm{P}_{\mathrm{IFN}(\mathrm{ACD}+)}\right.$-SEAP-pA) were subcutaneously inserted into wild-type mice, which were then percutaneously illuminated for $2 \mathrm{~h}$ with NIR light $(700 \mathrm{~nm})$. SEAP levels were profiled in the bloodstream of the treated animals after $24 \mathrm{~h}$. Non-illuminated mice or animals implanted with DGCL-deficient designer cells were used as negative controls. Data are mean \pm s.d.; statistics by two-tailed $t$-test; $n=5$ mice. ${ }^{\star} P<0.05$; NS, not significant.

transdermally illuminated the treated animals with NIR light and profiled the resulting SEAP levels in their bloodstream (Fig. 3).
Mind-controlled transgene expression in mammalian cells. By connecting the mind-triggered electrophysiological signals via an electroencephalography (EEG)-based BCI to the synthetic mammalian NIR light-triggered optogenetic signalling pathway, we designed a mind-genetic interface that uses brain waves to remotely control target gene transcription wirelessly. Therefore, an EEG headset was used to capture brain-wave activities and identify mental state-specific electrical patterns (discrete meditation-meter values, $0-100)$ resulting from self-trained biofeedback (maintaining the observed meditation-meter value within a desired range ${ }^{30}$ ), concentration (computer gaming) or meditation (relaxation; Fig. 4; Fig. 5a,b; Supplementary Fig. 5a,b). This BCI was set to power the NIR light and control the illumination time in response to meditation-meter threshold (Fig. 4). Human subjects wearing the EEG headset were thus able to intentionally programme the transgene expression of cultured $\mathrm{pSO} 3-/ \mathrm{pSO} 4-/$ pSTING-transgenic HEK-293T cells by mental states, such as biofeedback (Fig. 4a,b), concentration (Fig. 4c,d) or meditation (Fig. 4c,d). Non-illuminated pSO3-/pSO4-/pSTING-transgenic HEK-293T cells and DGCL-deficient pSO3-/pSTING-transgenic HEK-293T cells were used as negative controls (Fig. 4b,d).

A mind-controlled wireless-powered implant in mice. For mind-controlled transgene expression in mice, the BCI drove a field generator that wirelessly powered an inductively linked NIR light-containing implant enclosing $\mathrm{pSO} 3$-/pSO4-transgenic HEK-293F cells in serum-free suspension cultures (Fig. 5; Supplementary Fig. 5). The wireless-powered optogenetic implant 
a

Biofeedback

Meditation-meter value low

Meditation-meter value high

C

Mental state

Concentration

Meditation
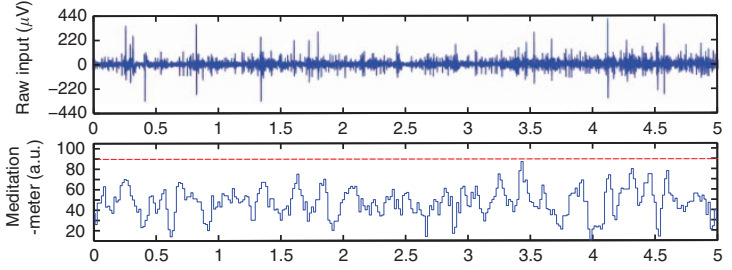

Time $(\min )$

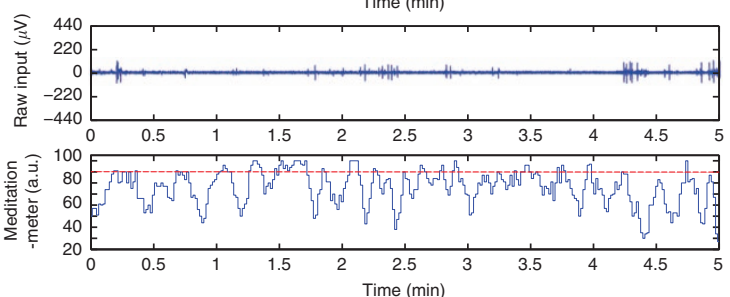

Time $(\min )$

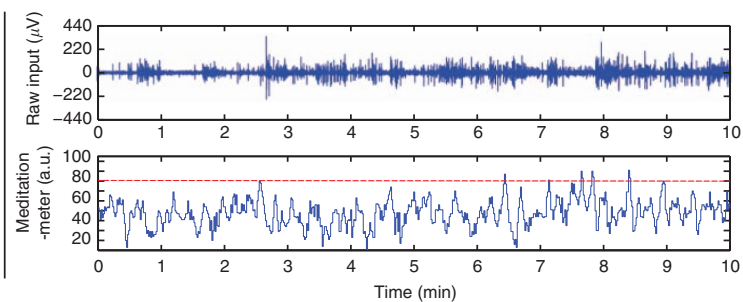

Time $(\min )$

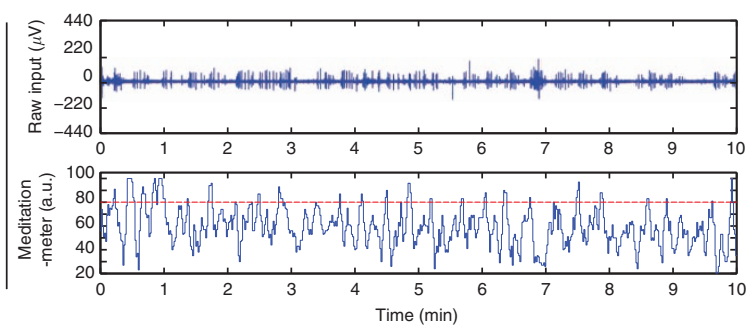

b

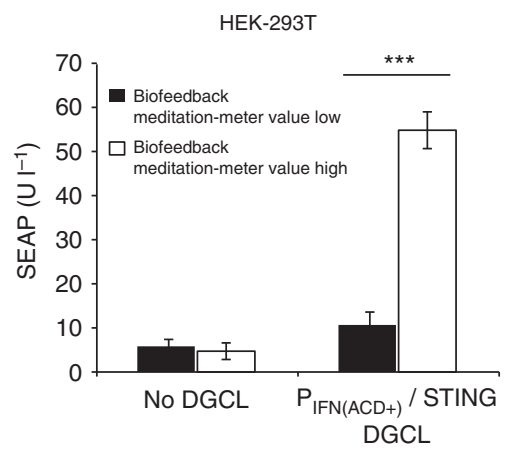

d

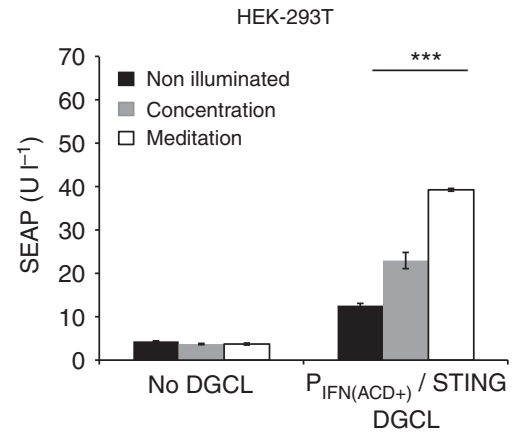

Figure 4 | The mind-controlled electro-optogenetic interface. (a,b) Biofeedback-controlled transgene expression switch in HEK-293T cells transgenic for

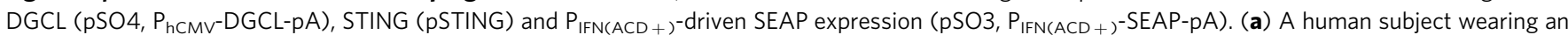
EEG headset, which captured brain-wave activities (raw input $(\mu \mathrm{V})$ ) and identified mental state-specific electrical patterns as discrete meditation-meter values (0-100), intentionally trained his/her mindset to maintain the biofeedback-derived meditation-meter value below (meditation-meter value low) or above (meditation-meter value high) a threshold value of 90 (dotted red line) by following the meditation-meter value displayed on the LCD computer screen in a biofeedback-controlled manner in real time. (b) Mind-controlled biofeedback-derived meditation-meter values above 90 triggered NIR light illumination of the engineered HEK-293T cells and programmed the optogenetic device of these designer cells to express SEAP. Meditation-meter values below 90 did not illuminate the designer cells, resulting in basal SEAP expression comparable to that of isogenic control HEK-293T populations deficient in DGCL expression. (c,d) Mental states, such as concentration and meditation, controlled the transgene expression in HEK-293T cells transgenic for DGCL

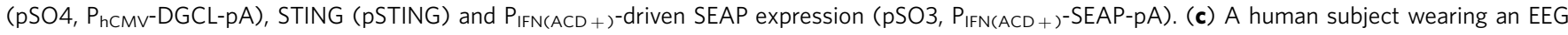
headset, which captured brain-wave activities (raw input $(\mu \mathrm{V})$ ) and identified mental state-specific electrical patterns as discrete meditation-meter values (0-100), generated mental states, such as concentration (computer gaming) and meditation (relaxation), without visual inspection of the displayed meditation-meter values (no biofeedback). The subject's mental state maintained the meditation-meter value below (concentration) or above (meditation) a threshold value of 80 (dotted red line). (d) Whenever the mental state drove the meditation-meter value above a threshold of 80 , the $\mathrm{BCI}$ triggered an NIR light pulse that illuminated the engineered HEK-293T cells. The designer cells integrated the NIR light pulses and produced a sustained high (meditation) or low (concentration) SEAP expression response. Isogenic non-illuminated HEK-293T populations and designer cells deficient in DGCL expression were used as negative controls. Data are mean \pm s.d.; statistics by two-tailed $t$-test; $n=6$. ${ }^{\star \star \star} P<0.001$.

(Fig. 5e; Fig. 6a; Supplementary Fig. 5e) consisted of a cultivation chamber with a semi-permeable $<300 \mathrm{kDa}$-cutoff membrane (Fig. 5e; Fig. 6a) to provide the molecular interface between the designer cells and the animal's peripheral circulation and a sealed electronic compartment (Fig. 5e; Fig. 6a; Supplementary Fig. 5e) in which the NIR LED was connected to the power-receiving antenna containing three orthogonal receiver coils (Fig. 5e; Fig. 6b; Supplementary Fig. 5e), which continuously powered the implant NIR LED (Fig. 5e; Fig. 6a-c; Supplementary Fig. 5e) as the animals moved freely (Fig. 6d) on the field generator (Fig. 5c; Fig. 6e; Supplementary Fig. 5c). The wireless-powered optogenetic implant electronics were validated by scoring the coupling intensity above the field generator (Supplementary Fig. 6) and confirming the molecular cutoff for viruses and bacteria (Supplementary Fig. 7).

When the pSO3-/pSO4-transgenic HEK-293F-containing wireless-powered optogenetic implants were placed subcutaneously on the back of wild-type mice moving on the field generator, the animals' blood SEAP levels could be controlled by the human subject's mental states, such as biofeedback (Fig. 7a-c), concentration (Fig. 7d-f) or meditation (Fig. 7d-f). Mindtriggered NIR light activation could be observed through the mouse skin in real time (Fig. 6d). Illuminated DGCLdeficient pSO3-transgenic HEK-293F implants (Fig. 7b,c,e,f) 


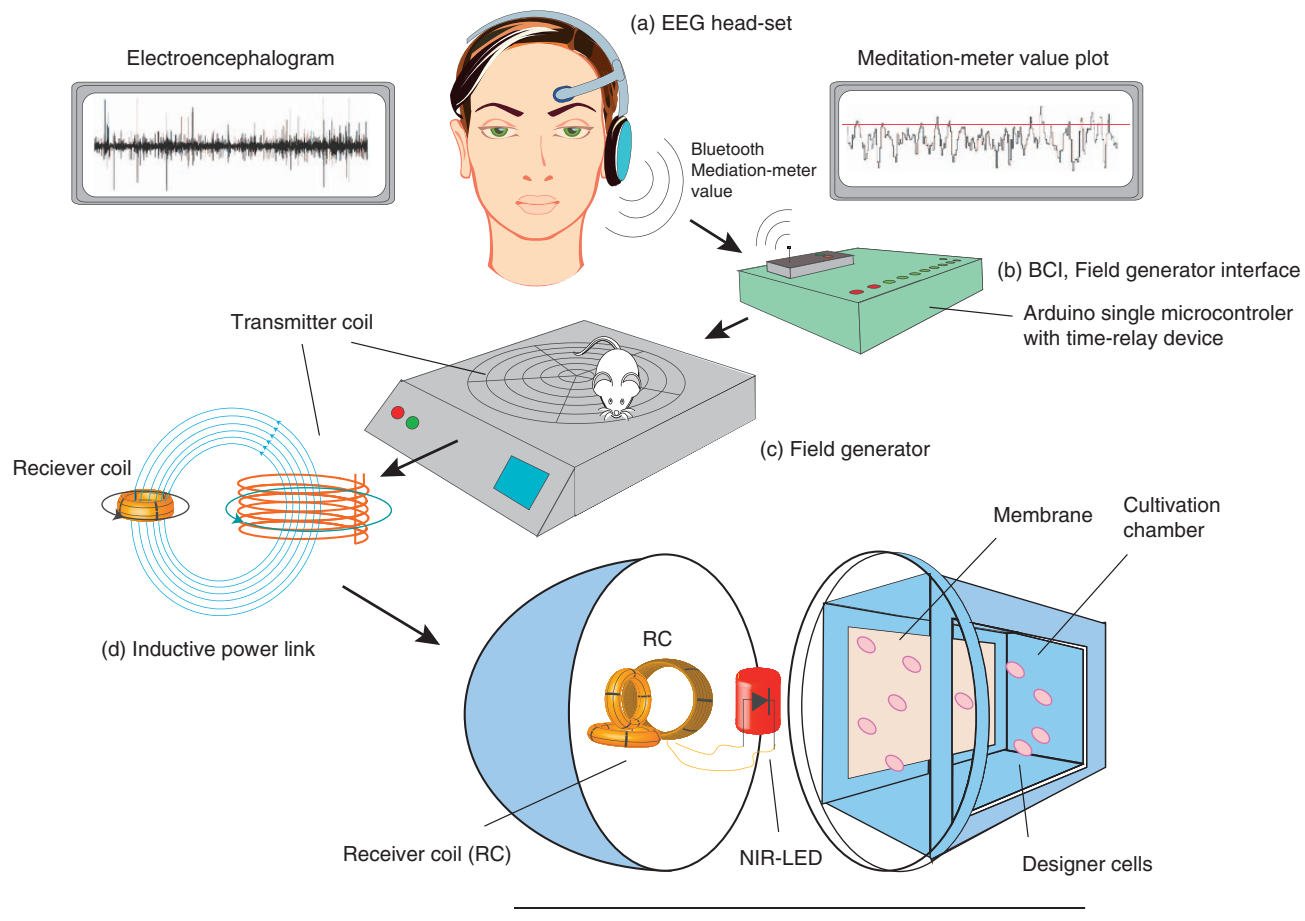

(e) Wireless-powered optogenetic implant

Figure 5 | Schematic representation of mind-controlled transgene expression. The mind-controlled transgene expression device consisted of (a) an EEG headset that captured brain-wave activities (the encephalogram), identified mental state-specific electrical patterns (biofeedback, concentration, meditation) and processed discrete meditation-meter values (0-100; meditation-meter value plot), which were transmitted via Bluetooth to (b) the Arduino single-board microcontroller with a time-relay device and switching the (c) field generator ON and OFF. This $\mathrm{BCl}$ (a-c) controlled (d) the TC $(\mathbf{c}, \mathbf{d})$ of the field generator, which inductively coupled with the (d,e) receiver coil (RC) of the (e) wireless-powered optogenetic implant. (e) The NIR light LED illuminated the culture chamber of the wireless-powered optogenetic implant and programmed the designer cells to produce SEAP, which diffused through the semi-permeable membrane. The blood SEAP levels of mice with subcutaneous wireless-powered optogenetic implants containing designer cells that were freely moving on the field generator could be modulated by the human subject's mindset in a wireless, remote-controlled manner.

(See Supplementary Fig. 5 for a schematic of the electronic components).

and non-illuminated pSO3-/pSO4-transgenic HEK-293F implants (Fig. 7e,f) were used as negative controls. Following removal of the wireless-powered optogenetic implants, the blood SEAP levels of the animals dropped rapidly (Supplementary Fig. 8) and high-level SEAP production of the designer cells inside the implant was confirmed (Fig. 7c,f).

\section{Discussion}

Cybernetics has pioneered mind-controlled electromechanical man-machine interfaces that allow brain activities to intentionally control bionic prostheses ${ }^{16}$, and optogenetics has established electromolecular machine-man interfaces that enable lightcontrolled therapeutic interventions by modulating brain ${ }^{31}$, heart $^{32}$ and gene activities ${ }^{1}$. By combining cybernetics with optogenetics, we now provide the missing link enabling mental states such as biofeedback, concentration and meditation to directly control the transgene expression in living cells and mammals. An ideal optogenetic device to interface with the BCI with transgene expression would have a simple design, be insensitive to pleiotropic input and provide robust, adjustable, reversible and rapid ON/OFF-switching profiles in response to light with deep-tissue penetration, negligible phototoxicity and address a chromophore that is available in the peripheral circulation. The NIR light-triggered synthetic optogenetic signalling pathway developed herein meets these criteria at a high standard. In particular, c-di-GMP is a mammalian cellcompatible orthogonal second messenger that is produced from intracellular GTP within minutes after NIR light illumination by ectopically expressed DGCL using biliverdin as the chromophore, a haem catabolic product that is abundant in mammalian circulation.

In addition, the endogenous c-di-GMP sensor STING rewires illumination to transcription by managing the activation of the engineered target promoters. Because the availability and abundance of the STING signalling componentry varies between different cell types, the synthetic optogenetic signalling pathway exhibits cell line-specific variations in performance. For example, while ectopic expression of human STING is essential for the NIR light optogenetic device in HEK-293T and boosts performance in human stem cells, it is dispensable in HEK-293F, which relies on endogenous STING for optimal performance. In addition, because HEK-293-derived cell lines do not produce hIFN- $\beta$ on activation of the c-di-GMP-based second messenger signalling pathway and are deficient in cGAS-mediated type-I interferon production $^{24}$ and STAT2 and IRF9 (ref. 33) expression, they are unable to trigger and fail to respond to paracrine hIFN- $\beta$ stimulation. Furthermore, the molecular cutoff of the cultivation chamber of the wireless-powered optogenetic device protects the designer cells from intracellular pathogens, making the synthetic optogenetic signalling pathway exclusive for NIR light input.

Currently available optogenetic devices programme the behaviour of implanted designer cells by percutaneous illumination using an extracorporeal light source ${ }^{1,2,32}$. Although NIR light, which is known for its deep-tissue penetration, was able to programme the product-gene expression of designer cells subcutaneously implanted into mice, we also developed a selfsufficient, removable wireless-powered optogenetic implant to 

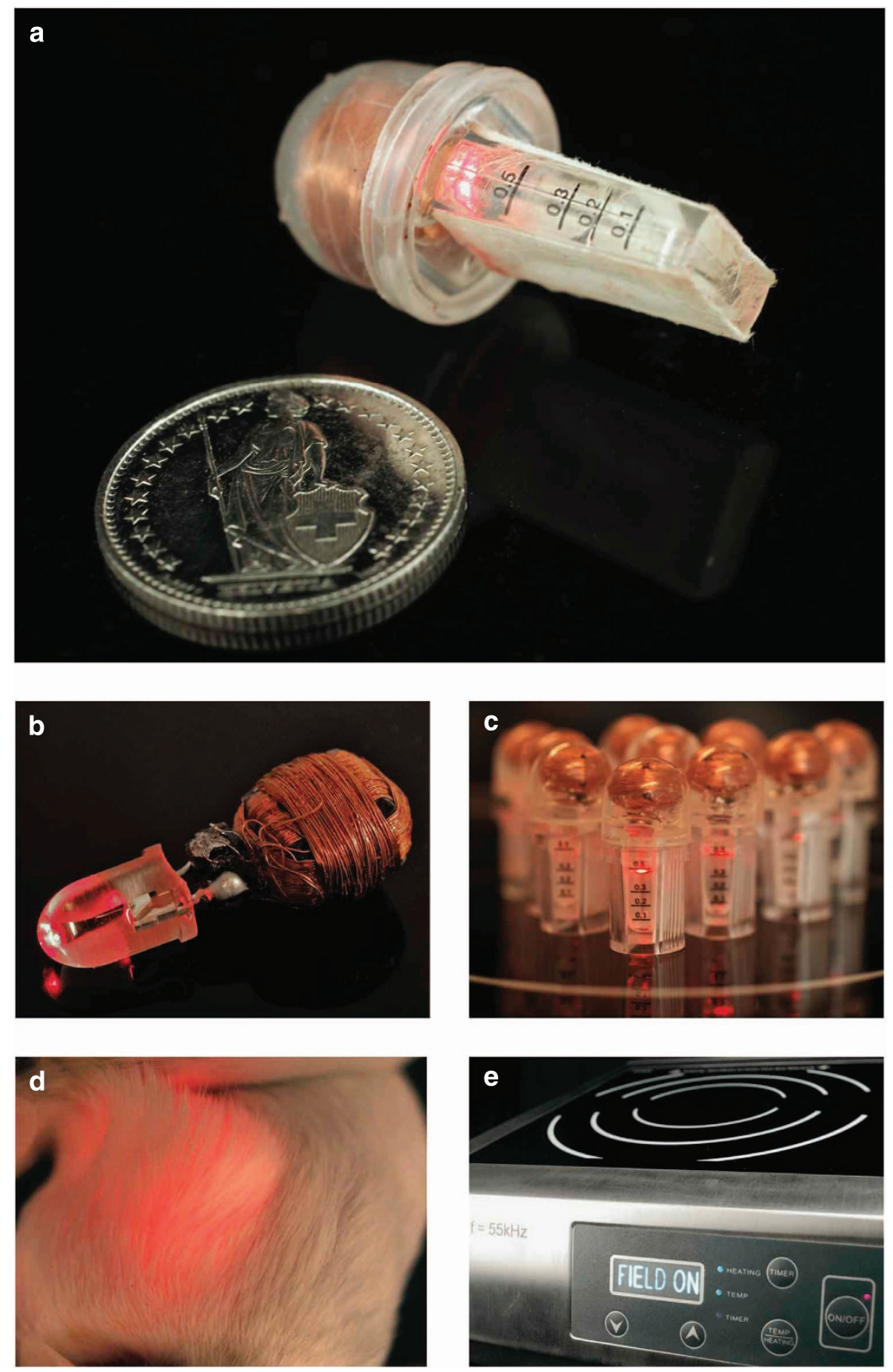

Figure 6 | Wireless-powered optogenetic implant. (a) Wireless-powered implant on the field generator with an illuminated NIR LED. A 1 CHF coin (23 mm in diameter) serves as a size indicator. The $0.5-\mathrm{ml}$ cultivation chamber containing semi-permeable PES membranes on both sides was moulded to a spherical polycarbonate cap contain a PDMS-sealed three-dimensional (3D) receiver antenna wired to the NIR-LED. (b) 3D receiver antenna wired via the receiver circuit (receiver coils, resonance capacitors, Schottky diodes; Supplementary Figs 5 and 11) to the NIR LED. (c) Quality-control test of the custommade wireless-powered optogenetic implants illuminated while standing on the powered field generator. (d) Mouse with a subcutaneous wireless-powered optogenetic implant, the activity of which can be observed through the skin. (e) Field generator.

combine placement flexibility and daylight insensitivity with optimal designer cell containment, maximum treatment compliance and host mobility. Wireless-powered optogenetic implants provide a highly modular interface that couples electronics with living cells and enables electronic devices to directly and remotely control gene expression. When coupled to brain activities, such electrogenetic devices provide mind-genetic interfaces that add a new dimension to state-of-the-art electronicmechanical implants, such as heart and brain pacemakers ${ }^{34}$, cochlear hearing aids ${ }^{35,36}$, eye prostheses ${ }^{37}$, insulin-releasing micropumps ${ }^{36}$ and bionic extremities ${ }^{16}$. Here we demonstrated that the transgene expression in mammalian cells and mice can be modulated by three different mental states: biofeedback, concentration and meditation. Far into the future, patients may either learn to generate specific mental states (for example, pain relief $\left.^{38}\right)$, locked-in syndrome $e^{15,39}$ programming or having disease-related brain activities (for example, epilepsy ${ }^{40,41}$, neurodegenerative disorders ${ }^{42}$ ) close-loop control, therapeutic implants producing corresponding doses of protein pharmaceuticals in real time. 
a

Biofeeback

Meditation-meter value low

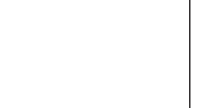

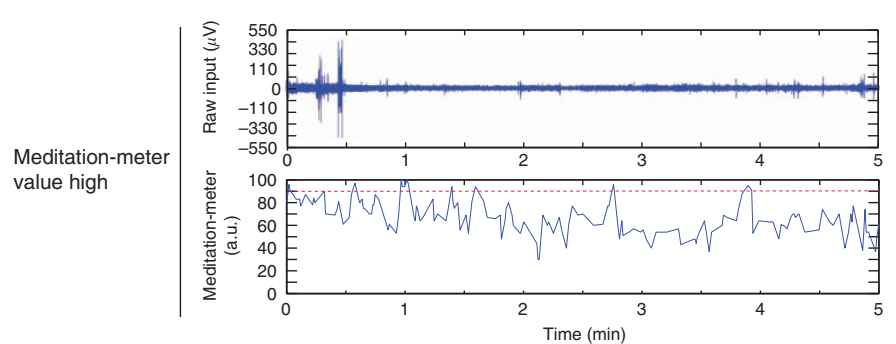

d

Mental state

Concentration

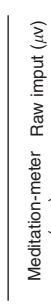

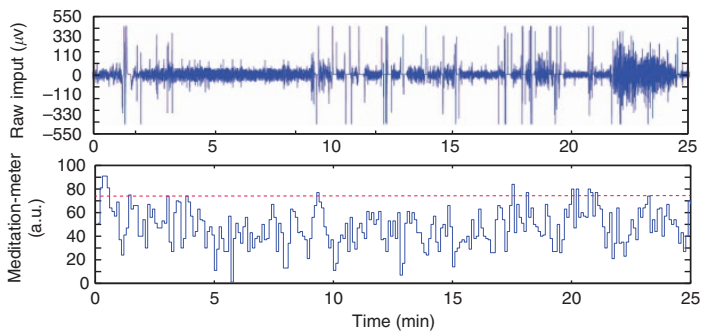

Meditation
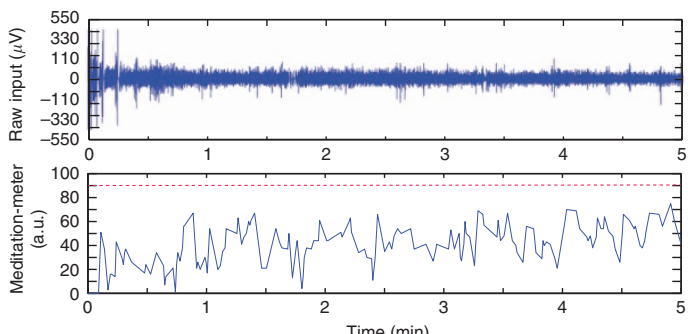

Time (min)

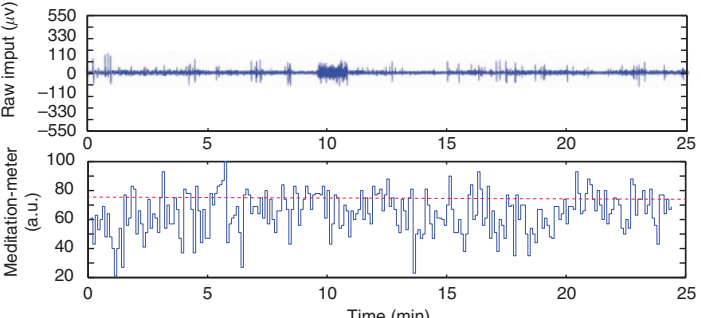

b
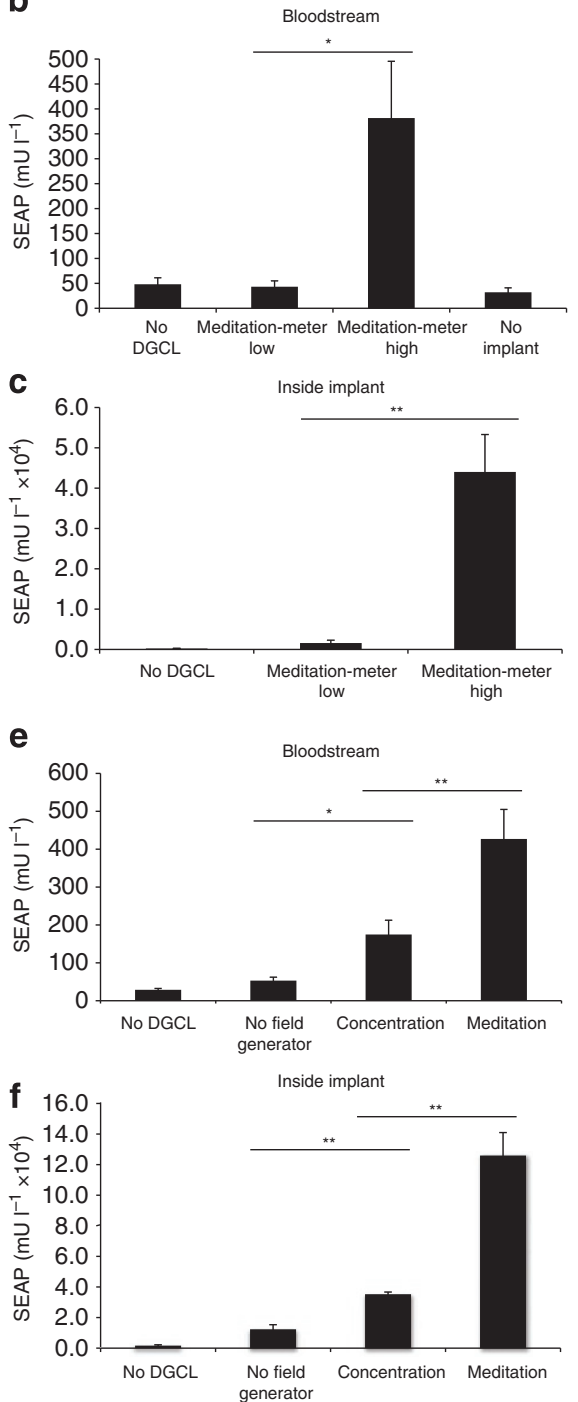

Figure 7 | Mind-controlled wireless-powered optogenetic implant in mice. (a-c) Biofeedback-controlled transgene expression in HEK-293F cells transgenic for DGCL (pSO4) and $\mathrm{P}_{\mathrm{IFN}(\mathrm{ACD}+\text { ) }}$-driven SEAP expression (pSO3) contained in a wireless-powered optogenetic implant (Fig. 5, Supplementary Fig. 5). (a) A human subject wearing an EEG headset capturing brain-wave activities (raw input $(\mu \mathrm{V})$ ) and providing discrete meditation-meter values (0-100), trained his/her mindset to maintain the biofeedback-derived meditation-meter value below (meditation-meter value low) or above (meditationmeter value high) a threshold value of 90 (dotted red line) (b,c) Mind-controlled meditation-meter values above 90 activated a field generator, inductively powered the subcutaneous wireless optogenetic implant inside the mice freely moving in the field generator, illuminated the culture chamber, thereby programming the designer cells to secrete SEAP that was measured in the animals' bloodstream (b) and the implant chamber. (c) Isogenic DCL-deficient HEK-293F cells and mice without implants served as negative controls. (d-f) Mental states controlling transgene expression in HEK-293F cells transgenic for DGCL (pSO4) and $\mathrm{P}_{\mathrm{IFN}(\mathrm{ACD}+\text { ) }}$-driven SEAP expression ( $\mathrm{pSO3)}$ contained in a wireless-powered optogenetic implant. (d) A human subject wearing an EEG headset, capturing brain-wave activities (raw input $(\mu \mathrm{V})$ ) and providing discrete meditation-meter values (0-100), generated specific mental states, such as concentration (computer gaming) and meditation (relaxation), without visual inspection of the displayed meditation-meter values (no biofeedback). The subject's mental state maintained the meditation-meter value below (concentration) or above (meditation) a threshold value of 75 (dotted red line). (e,f) Mind-controlled meditation-meter values above 75, activated a field generator, inductively powered the subcutaneous wireless optogenetic implant inside the mice freely moving in the field generator, illuminated the culture chamber, thereby programming the designer cells to secrete SEAP that was measured in the animals' bloodstream (e) and the implant chamber (f). Isogenic DCL-deficient HEK-293F cells and treated mice not exposed to the field generator were used as negative controls. Data are mean \pm s.d.; statistics by two-tailed $t$-test; $n=5$ mice. ${ }^{\star} P<0.05$, ${ }^{\star \star} P<0.01$.

\section{Methods}

Mind-controlled optogenetic components. Comprehensive design and construction details for all expression vectors are provided in Supplementary Table 1. The integrity of all relevant genetic components was confirmed by sequencing (Microsynth, Balgach, Switzerland). The key plasmids used were as follows: pSO3, which contains SEAP under the control of an optimized hIFN- $\beta$ promoter

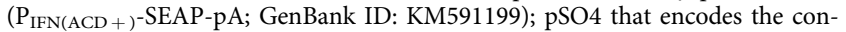
stitutive expression of a human codon-optimized PDE domain-deficient NIR lightactivated DGCL derived from Rhodobacter sphaeroides BphG1 ( $\mathrm{P}_{\mathrm{hCMV}}$-DGCL-pA; N-terminal PAS-GAF-PHY-GGDEF portion of BphG1 (Q8VRN4_RHOSH), catalytic DGCL domain GGDEF photoactivated by its cognate PAS-GAF-PHY phytochrome; GenBank ID: (Genbank ID: KM591197)); and pSTING that mediates constitutive expression of mouse STING.

Cell culture and transfection. Human embryonic kidney cells (HEK-293T, ATCC: CRL-11268) and immortalized hMSCs ${ }^{43}$ were cultivated in Dulbecco's modified Eagle's medium (Invitrogen, Basel, Switzerland) supplemented with 10\% fetal bovine serum (FBS; cat. no. F7524, lot no. 022M3395, Sigma-Aldrich, Munich, Germany) and 1\% (v/v) penicillin/streptomycin solution (Sigma-Aldrich, Munich, Germany). HEK-293-derived FreeStyle 293F suspension cells (HEK-293F; Invitrogen) were grown in FreeStyle 293 expression medium (Invitrogen). 
All cell types were cultivated at $37^{\circ} \mathrm{C}$ in a humidified atmosphere containing $5 \%$ $\mathrm{CO}_{2}$. Cell concentration and viability were profiled with a CASY Cell Counter and Analyser System Model TT (Roche Diagnostics, Mannheim, Germany). For (co)transfection, $5 \times 10^{4}$ HEK-293T, HEK-293F or hMSCs were diluted in $0.4 \mathrm{ml}$ of culture medium and seeded per well of a 24 -well plate $12 \mathrm{~h}$ before (co)-transfection. The cells were then incubated for $6 \mathrm{~h}$ with $200 \mu \mathrm{l}$ of a 1:2 PEI:DNA mixture (w/w) (polyethyleneimine; MW 40,000, Polysciences, Inc., Warrington, USA) containing $1 \mu \mathrm{g}$ of total DNA (for co-transfections, an equal amount of plasmid DNA was used unless otherwise indicated). After (co)-transfection, the culture medium was replaced, and the engineered cells were used for a dedicated experiment, which was typically analysed for $48 \mathrm{~h}$

Production and transduction of lentiviral particles. To produce enhanced yellow fluorescent protein (EYFP)-expressing lentiviral particles, HEK-293T cells $\left(5 \times 10^{5}\right.$ cells per well of a six-well plate) were co-transfected by incubating the cells for $6 \mathrm{~h}$ with $200 \mu \mathrm{l}$ of a 1:2 PEI:DNA mixture containing $1 \mu \mathrm{g}$ of pLTR-G, which encodes the constitutive expression of the vesicular stomatitis virus $G$ protein ${ }^{44}$, $1 \mu \mathrm{g}$ of the helper plasmid pCD/NL/BH ${ }^{*}$ (ref. 45) and $2 \mu \mathrm{g}$ of pNLK8 $\left(5^{\prime} \mathrm{LTR}-\psi^{+}\right.$ ori $_{S V 40^{-}}$-CPPT-RRE-P $\mathrm{hEFI}{ }^{-}$-EYFP- $\left.3^{\prime} \mathrm{LTR}_{\Delta \mathrm{U} 3}\right)^{46}$. The lentiviral particles were collected from the culture supernatant $48 \mathrm{~h}$ after transfection and quantified as described previously ${ }^{44,47}$. In brief, lentiviral transduction units were estimated by transduction of $5 \times 10^{5}$ HEK-293T cells with serially diluted lentiviral particles and subsequent quantification of the transduced cells by fluorescence microscopy. To validate the virus-specific $300-\mathrm{kDa}$ molecular weight cutoff of the implant membrane, we sequentially injected $5 \times 10^{5}$ HEK- $293 \mathrm{~F}$ cells and $5 \times 10^{5} \mathrm{EYFP}-$ encoding lentiviral particles ( $24 \mathrm{~h}$ later) into the implant and placed the sealed implant in a culture vial containing $5 \times 10^{5}$ HEK- $293 \mathrm{~F}$ cells. After $72 \mathrm{~h}$, EYFPfluorescent cells were visualized by fluorescence microscopy.

Fluorescence microscopy. EYFP expression by HEK-293F was visualized using a Leica DM-IL equipped with a DC300 FX camera (Leica Microsystems, Heerbrugg, Switzerland) and a YFP S filter system.

SEAP assay. Production of human placental SEAP was quantified in culture supernatants according to a $p$-nitrophenylphosphate-based light absorbance time course $^{48}$. SEAP levels of serum, which was isolated from blood samples using microtainer SST tubes (Becton Dickinson, Plymouth, UK), were profiled using a chemiluminescence-based assay (Roche Diagnostics).

c-di-GMP assay. c-di-GMP was detected in cells using a genetically encoded c-di-GMP-specific FRET biosensor consisting of the central Salmonella typhimurium-derived diguanylate receptor domain YcgR flanked by yellow (mYPet) and cyan (mCYPet) fluorescent protein domains (mYPet-YcgR-mCYPet $)^{49}$. The fluorescent protein domains are in closest proximity in the absence of c-di-GMP, with maximal FRET, and the FRET signal dose dependently decreases as c-di-GMP binds YcgR, which alters the relative orientation of the FRET pair mYPet and mCYPet. The FRET biosensor was expressed in pET15b::mYPet-ycgRmCYPet-transformed Escherichia coli and affinity purified via its $\mathrm{N}$-terminal polyhistidine $\operatorname{tag}^{49}$.

For the in vitro FRET-based analysis of intracellular c-di-GMP levels in mammalian cells, $5 \times 10^{4}$ cells were collected by centrifugation $(2 \mathrm{~min}, 4,500 \mathrm{~g}$, $\left.20{ }^{\circ} \mathrm{C}\right)$ and lysed in $0.5 \mathrm{ml}$ of ice-cold acetonitrile $/ \mathrm{CH}_{3} \mathrm{OH} / \mathrm{ddH}_{2} \mathrm{O}(2: 2: 1, \mathrm{v} / \mathrm{v} / \mathrm{v})$ by sequential incubation on ice $(15 \mathrm{~min})$ and $95^{\circ} \mathrm{C}(5 \mathrm{~min})$. The cell lysate was cleared of cell debris by centrifugation $\left(5 \mathrm{~min}, 14,000 \mathrm{~g}, 4^{\circ} \mathrm{C}\right)$ and the supernatant was vacuum dried for $120 \mathrm{~min}$ at $40^{\circ} \mathrm{C}$. The pellet was resuspended in $12 \mu \mathrm{l}$ of PBS $\left(137 \mathrm{mM} \mathrm{NaCl}, 2.7 \mathrm{mM} \mathrm{KCl}, 4.3 \mathrm{mM} \mathrm{Na}_{2} \mathrm{HPO}_{4}, 1.4 \mathrm{mM} \mathrm{KH}_{2} \mathrm{PO}_{4} ; \mathrm{pH} 7.4\right)$ and then serially diluted in PBS. For FRET-based c-di-GMP quantification, $5 \mu \mathrm{l}$ of serially diluted mammalian cell extracts and $10 \mu \mathrm{l}$ of mYPet-YcgR-mCYPet $(50 \mathrm{nM}$, in PBS pH 7.4) were mixed in each well of a 384-well plate, and the FRET ratio of excitation $(425 \mathrm{~nm})$ and emission $(535 \mathrm{~nm})$ was profiled using an EnVision 2104 multilabel plate reader equipped with a quad monochromator (excitation at $425 \mathrm{~nm}$, emission scan between 460 and $560 \mathrm{~nm}$ at 2-nm intervals; PerkinElmer, Waltham, MA, USA). The calibration curve using recombinant myPet-YcgR$\mathrm{mCyPet}$ protein was linear within the range of $10 \mathrm{nM}$ to $1 \mu \mathrm{M}$ c-di-GMP.

mYPet-YcgR-mCYPet was also used for FRET-based detection of c-di-GMP levels in living mammalian cells. Therefore, HEK-293T cells were (co)-transfected with pKZY81 ( $\mathrm{P}_{\mathrm{Sv} 40}$-mYPet-YcgR-mCyPet-pA) alone or together with pKZY121 $\left(\mathrm{P}_{\mathrm{SV} 40}-\mathrm{DGCA}_{\mathrm{CC} 3285}-\mathrm{pA} ; 4: 1 \mathrm{ratio}\right)$. After $24 \mathrm{~h}$, the transfected cells were washed once with PBS and placed in a black 96-well plate $\left(2.5 \times 10^{5}\right.$ cells per well), and FRET was profiled as described above.

hIFN- $\beta$ assay. human IFN- $\beta$ was quantified by ELISA (VeriKine Human IFN- $\beta$ ELISA Kit no. 41410; PBL Assay Science, Lausen, Switzerland). Paracrine stimulation of $\mathrm{P}_{\mathrm{IFN}(\mathrm{ACD}+)}$ ) was tested by transfecting $5 \times 10^{4}$ HEK-293T cells with

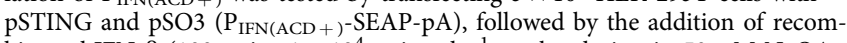
binant hIFN- $\beta$ (100 units, $1 \times 10^{4}$ units $\mathrm{ml}^{-1}$ stock solution in $50 \mathrm{mM} \mathrm{NaOAc}$, $0.1 \%$ BSA, pH 5.5; no. 11415-1; PBL, Assay Science). As a positive control for STING activation, $50 \mathrm{\mu g} \mathrm{ml}^{-1}$ DMXAA (5,6-dimethylxanthenone-4-acetic acid,
$10 \mathrm{mg} \mathrm{ml}^{-1}$ stock solution in dimethylsulphoxide; Santa Cruz Biotechnology, Santa Cruz, CA, USA) was used.

Optogenetic transgene expression in mammalian cells. HEK-293T/HEK-293F cells transgenic for pSO3, pSO4 and pSTING were cultivated in colourless phenol red-free Dulbecco's modified Eagle's medium/FreeStyle 293 expression medium (Invitrogen) supplemented with $25 \mu \mathrm{M}$ biliverdin hydrochloride (Livchem, Frankfurt am Main, Germany), a haemoglobin catabolite taken up by cells and serving as a DCGL chromophore ${ }^{50-52}$. The 12 -well culture plates were placed $7 \mathrm{~cm}$ below a custom-designed $3 \times 4$ LED panel (each LED centred above a single well; $\lambda_{\max }=700 \mathrm{~nm}, 20 \mathrm{~mW} \mathrm{sr}^{-1}$; cat. no. ELD-700-524-1; Roithner Lasertechnik $\mathrm{GmbH}$, Vienna, Austria) and constantly illuminated for different periods of time $(5,15,60,120 \mathrm{~min})$. SEAP levels were quantified in the culture supernatant after $48 \mathrm{~h}$.

Optogenetic remote control of transgene expression in mice. Subcutaneous implants were produced by seeding $5 \times 10^{4}$ pSO3-, pSO4- and pSTING-transgenic HEK-293T cells into 2.5-cm CellMax hollow-fibre membranes (Spectrum Laboratories Inc., Rancho Dominguez, CA, USA) and heat-sealing both ends using a Webster smooth needle holder (Harvard Apparatus, Holliston, MA, USA; cat. no. 512467). Following dorsal subcutaneous implantation into short-term isofluraneanaesthetized wild-type mice (Oncins France souche 1, Charles River Laboratories, Lyon, France), the animals were directly illuminated for $2 \mathrm{~h}$ using a $4 \times 8$ LED (690 nm, $18 \mathrm{~mW} \mathrm{sr}^{-1}$; Infors, Bottmingen, Switzerland) placed $10 \mathrm{~cm}$ above the standard animal cage. After $48 \mathrm{~h}$, the animals were killed, blood samples were collected and the serum was isolated using microtainer SST tubes according to the manufacturer's protocol (Becton Dickinson, Plymouth, UK). Serum SEAP levels were then quantified as described above.

Mind-controlled transgene expression. The synthetic mind-genetic interface that allows mind-controlled transgene expression in a living organism requires different serially linked electronic, optic and genetic components: (i) The BCI (Fig. 5a,b; Supplementary Fig. 5a,b) captures brain waves, processes these electronic signals and provides a, mental state-based (biofeedback, concentration, meditation) electronic output that switches the (ii) field generator ON and OFF (Fig. 5c; Fig. 6e; Supplementary Fig. 5c). The transmitter coil (TC; Fig. 5d; Supplementary Figs 5d, 9 and 10) of the field generator produces an alternating electromagnetic field that inductively couples with the receiver coil (Fig. 5d,e; Fig. 6b; Supplementary Fig. 5d,e) to wirelessly power and programme the (iii) wireless-powered optogenetic implant (Fig. 5e; Fig. 6a-c; Supplementary Fig. 5e) to switch transgene expression of the designer cells inside ON and OFF in a light-dependent and mind-controlled manner.

BCI. We used a standard commercial low-cost BCI headset (MindSet; NeuroSky Inc., San Jose, USA), which digitizes the brain-wave $\mathrm{EEG}^{53-56}$ (Fig. 5a; Supplementary Fig. 5a). This headset places one dry EEG sensor on the left forehead (two centimeters above the eyebrow) targeting the frontal cortex where cognitive signals linked to higher states of consciousness originate as well as three dry reference electrodes on the left ear and records the following EEG-based information: raw EEG $(1 \mathrm{~Hz}$, analogue-to-digital conversion rate), signal quality (0, good signal; 1, poor signal level; off-head state of the EEG sensor); EEG delta band $(0.5-2.75 \mathrm{~Hz})$; EEG theta band $(3.5-6.75 \mathrm{~Hz})$; EEG low alpha band $(7.5-9.25 \mathrm{~Hz})$; EEG high alpha band $(10-11.75 \mathrm{~Hz})$; EEG low beta band $(13-16.75 \mathrm{~Hz})$; EEG high beta band $(18-29.75 \mathrm{~Hz})$; EEG low gamma band $(31-39.75 \mathrm{~Hz})$; EEG mid gamma band $(41-49.75 \mathrm{~Hz})$. The headset's microprocessor executes a proprietary algorithm computing a fast Fourier transformation to convert a wide spectrum of brain waves in both time and frequency domains including alpha and beta waves into attention (emphasis on beta waves indicating the user's mental focus, $14-30 \mathrm{~Hz}$ ) and meditation (emphasis on alpha waves indicating the user's mental calmness, $7.5-12 \mathrm{~Hz}$ )-meter values (integer values $0-100$ ) that are corrected for eye movement (eye-blinking score, integer value $0-255$ ) and filtered for noise resulting from head movements and muscle artifacts ${ }^{57,56}$. The collected data sets are transmitted via Bluetooth (raw data, $\mathrm{ms}^{-1}$; processed data, $\mathrm{s}^{-1}$ ) for storage, display on a screen or control of the optogenetic device and wireless-powered implant (see below).

For all mind-control experiments, the subjects sat in a comfortable chair in front of an LCD computer screen wearing the BCI headset and keeping the eyes open at all times. The LCD screen was controlled by a Laptop computer connected to the headset through a bluetooth serial connection. The subjects were verbally instructed to generate three different mental states: biofeedback, concentration and meditation. To generate the biofeedback mental state, the subject was asked to watch the meditation-meter values displayed on a screen and self-train to keep the meditation-meter values above and below a desired threshold. To reach the mental state of concentration, the subject was playing the computer game minesweeper, and for meditation, the subjects were asked to breathe deeply while looking at a landscape still picture on the LCD screen. Unlike for the biofeedback, the subjects did not train to produce mental states of concentration and meditation, as they did not obtain real-time feedback on the screen about their mental states. 
The meditation-meter values of the human subjects were transferred from the BCI headset to the Arduino single-board microcontroller (Arduino Uno, Dangi Internet Electronics, Granada, Spain; http://developer.neurosky.com/docs/ doku.php?id=mindwave_mobile_and_arduino) in a serial data stream via Bluetooth (BlueSMiRF Gold Bluetooth modem WRL-10268 (SparkFun Electronics, Boulder, CO, USA)) programmed with media access control software and the CleanProgramBlueSMiRF.pde script (NeuroSky Modified by Sean Montgomery; www.developer.neurosky.com; Fig. 5b; Supplementary Fig. 5b). The programme running on the Arduino single-board microcontroller (MindSETArduinoReader. pde; NeuroSky modified by Sean Montgomery; www.developer.neurosky.com) converted the meditation-meter values into 10 discrete levels, which were visualized using a 10-LED bar along with control LEDs indicating error and signal quality (Fig. 5b; Supplementary Fig. 5b). The data stream could be collected by a computer using the Arduino single-board microcontroller's serial port running the MindSETArduinoViewer.pde processing script (NeuroSky modified by Sean Montgomery; www.developer.neurosky.com) and used to directly switch a NIR LED panel (see above) or the field generator ON or OFF for a specific period of time via a multifunctional USB time-relay device interface (cat. no. 1190035; H-TRONIC, Hirschau, Germany; Fig. 5b; Supplementary Fig. 5b).

To validate the response dynamics of the BCI in cell culture, $\mathrm{pSO} / \mathrm{pSO} 4 /$ pSTING-transgenic HEK-293T cells $\left(5 \times 10^{4}\right.$ cells per well of a 24 -well plate) were exposed to mind-controlled illumination by the NIR LED panel, and the resulting SEAP production was profiled in the culture supernatant after $24 \mathrm{~h}$. The human subject wearing the $\mathrm{BCI}$ headset performed three different mental states: a selftrained biofeedback mental state (maintaining the observed meditation-meter values on the 10-LED indicator within a desired range); a concentration-based mental state (computer gaming); and a meditation-based mental state (relaxation), all of which were integrated and converted to threshold-dependent activation of the time-delay relay that switched the NIR LED panel ON for a defined period of time (biofeedback: integration, $5 \mathrm{~min}$; threshold, meditation-meter value 90; LED panel activation, $15 \mathrm{~min}$; concentration and meditation: integration, $15 \mathrm{~min}$; threshold, meditation-meter values 80; LED panel activation, $15 \mathrm{~s}$ ).

The field generator. The case and the flat coil (FC) (Supplementary Fig. 9) were derived from an induction cooker (IKBE-BT-350KC, Kibernetik AG, Buchs, Switzerland; Fig. 5c; Fig. 6e; Supplementary Figs $5 c$ and 9). The FC contained 21 turns (50 $\mathrm{mm}$ inner and $180 \mathrm{~mm}$ outer diameter) of a copper thread assembled from 50 parallel $0.35-\mathrm{mm}$ copper wires to minimize electrical resistance (Supplementary Fig. 9). Eight rectangular $(50 \times 18 \times 5 \mathrm{~mm})$ ferrite bars were astrally fixed at the bottom of the FC to guide the field lines and increase the magnetic efficiency (Supplementary Fig. 9). To construct the TC, the FC was connected to a parallel capacitor, a power-managing metal-oxide-semiconductor field-effect transistor (MOSFET) and a pulse-producing synthesized function generator setting the circuit to a frequency of $55 \mathrm{kHz}$ (Supplementary Fig. 10). To maintain the TC in resonance, it was connected to a resonance detection circuit, which feedback controlled the MOSFET. The energy for the resonance detection circuit $(15 \mathrm{~V}$ d.c.) and MOSFET ( $63 \mathrm{~V}$ d.c.) was provided by a power supply. The TC received its instructions from the BCI via an enable circuit (Supplementary Fig. 5). The TC was fitted into the induction-cooker casing and used as the field generator to produce the magnetic field powering and remote-controlling the wireless-powered optogenetic implant.

Wireless-powered optogenetic implant. The wireless-powered optogenetic implant was a fully sealed, all-in-one biocompatible device comprising a power receiver, which was remotely powered by electromagnetic induction controlled by the field generator, and the 700-nm NIR LED $\left(\lambda_{\max }=700 \mathrm{~nm}, 20 \mathrm{~mW} \mathrm{sr}^{-1}\right.$; cat. no. ELD-700-524-1; Roithner Lasertechnik, Vienna, Austria), which enabled lightprogrammable transgene expression of designer cells inside the semi-permeable cultivation chamber (Fig. 5e; Fig. 6a-c; Supplementary Fig. 5e). The power receiver's antenna was assembled from three orthogonal copper coils $(0.1-\mathrm{mm}$ copper wire with 130 windings on a $7 \times 7 \times 7 \mathrm{~mm}$ ferrite cube), three in-series resonance capacitors and six Schottky diodes, which integrated and rectified the current of the three coils and powered the NIR LED in an orientation- and motionindependent manner (Fig. 5d,e; Fig. 6b; Supplementary Figs 5d,e and 11). The entire power receiver, including the base of the NIR LED, was moulded into a spherical polycarbonate cap containing polydimethylsiloxane (PDMS; cat. no. 701912-1, Sigma-Aldrich, Buchs, Switzerland) and fitted to a custom-adapted 500$\mu$ polycarbonate chamber $(0.4 \times 0.9 \mathrm{~mm})$ with semi-permeable polyethersulfone $<300 \mathrm{kDa}$-cutoff membranes (PES Membrane, VS0651, Sartorius Stedim Biotech, Germany) on two sides (Fig. 5e; Fig. 6a; Supplementary Fig. 5e). The device was sealed by polymerizing the PDMS for $30 \mathrm{~min}$ at $50{ }^{\circ} \mathrm{C}$. The coupling intensity of the wireless-powered optogenetic implant was profiled in the space above the field generator by scoring the wireless transmission of power to the implant (Supplementary Fig. 6). A total of $500 \mu \mathrm{l}$ of a pSO3/pSO4- or pSO3/pSBC-2 (negative control)-transgenic HEK-293F cell suspension $\left(1 \times 10^{6}\right.$ cells) was loaded via a syringe through a hole in the polycarbonate side of the culture chamber, which was sealed with a PDMS plug before implanting the device subcutaneously into the mouse.
Mind-controlled transgene expression in mice. Cell-containing wirelesspowered optogenetic implants were subcutaneously implanted on the backs of short-term isoflurane-anaesthetized wild-type mice (Oncins France souche 1, Charles River Laboratories, Lyon, France), and the cage containing the treated animals was placed on the field generator connected to the $\mathrm{BCI}$. The human subject wearing the $\mathrm{BCI}$ headset conducted three different mental states, biofeedback, concentration and meditation, which were integrated (5/25/25 min) and converted to threshold (meditation-meter values 90/75/75)-dependent activation of the timedelay relay that switched the NIR LED in the wireless-powered optogenetic implant ON for defined periods of time $(60 \mathrm{~min} / 30 \mathrm{~s} / 30 \mathrm{~s})$ and induced light-triggered SEAP expression in the implanted cells. After 48 and $144 \mathrm{~h}$, blood samples were collected retro-orbitally, and serum SEAP levels were determined as described above. The implants of one treatment group were removed after SEAP profiling at $48 \mathrm{~h}$, and the serum SEAP levels were quantified again $96 \mathrm{~h}$ after implant removal. Control mice received wireless-powered optogenetic implants containing pSO3/ pSBC-2-transfected HEK-293F cells. Throughout the entire animal study, five 4-week-old female Oncin Souche 1 wild-type mice of the delivered pool were randomly allocated to the individual treatment groups. Neither samples nor animals were excluded from the study and blood-sample analysis was blinded. All experiments involving animals were performed according to the directives of the European Community Council (2010/63/EU), approved by the French Republic (no. 69266310), and performed by Marie Daoud-El Baba at the Institut Universitaire de Technology, IUTA, F-69622 Villeurbanne Cedex, France.

\section{References}

1. Ye, H., Daoud-El Baba, M., Peng, R. W. \& Fussenegger, M. A synthetic optogenetic transcription device enhances blood-glucose homeostasis in mice. Science 332, 1565-1568 (2011).

2. Wang, X., Chen, X. \& Yang, Y. Spatiotemporal control of gene expression by a light-switchable transgene system. Nat. Methods 9, 266-269 (2012).

3. Weber, W. et al. Gas-inducible transgene expression in mammalian cells and mice. Nat. Biotechnol. 22, 1440-1444 (2004).

4. Stanley, S. A. et al. Radio-wave heating of iron oxide nanoparticles can regulate plasma glucose in mice. Science 336, 604-608 (2012).

5. Tigges, M., Marquez-Lago, T. T., Stelling, J. \& Fussenegger, M. A tunable synthetic mammalian oscillator. Nature 457, 309-312 (2009).

6. Tigges, M., Denervaud, N., Greber, D., Stelling, J. \& Fussenegger, M. A synthetic low-frequency mammalian oscillator. Nucleic Acids Res. 38, 2702-2711 (2010).

7. Xie, Z., Wroblewska, L., Prochazka, L., Weiss, R. \& Benenson, Y. Multi-input RNAi-based logic circuit for identification of specific cancer cells. Science 333, 1307-1311 (2011).

8. Nissim, L. \& Bar-Ziv, R. H. A tunable dual-promoter integrator for targeting of cancer cells. Mol. Syst. Biol. 6, 444 (2010).

9. Auslander, S., Auslander, D., Muller, M., Wieland, M. \& Fussenegger, M. Programmable single-cell mammalian biocomputers. Nature 487, 123-127 (2012).

10. Weber, W. \& Fussenegger, M. Emerging biomedical applications of synthetic biology. Nat. Rev. Genet. 13, 21-35 (2012).

11. Kemmer, C. et al. Self-sufficient control of urate homeostasis in mice by a synthetic circuit. Nat. Biotechnol. 28, 355-360 (2010).

12. Auslander, D. et al. A synthetic multifunctional mammalian $\mathrm{pH}$ sensor and CO2 transgene-control device. Mol. Cell 55, 397-408 (2014).

13. Rössger, K., Charpin-El-Hamri, G. \& Fussenegger, M. A closed-loop synthetic gene circuit for the treatment of diet-induced obesity in mice. Nat. Commun. 4 , 2825 (2013).

14. Wang, W. et al. Neural interface technology for rehabilitation: exploiting and promoting neuroplasticity. Phys. Med. Rehabil. Clin. N. Am. 21, 157-178 (2010).

15. Daly, J. J. \& Wolpaw, J. R. Brain-computer interfaces in neurological rehabilitation. Lancet Neurol. 7, 1032-1043 (2008).

16. Hochberg, L. R. et al. Neuronal ensemble control of prosthetic devices by a human with tetraplegia. Nature 442, 164-171 (2006).

17. Galan, F. et al. A brain-actuated wheelchair: asynchronous and non-invasive brain-computer interfaces for continuous control of robots. Clin. Neurophysiol. 119, 2159-2169 (2008).

18. Chow, B. Y. \& Boyden, E. S. Optogenetics and translational medicine. Sci. Transl. Med. 5, 177ps5 (2013).

19. Jayakumar, M. K., Idris, N. M. \& Zhang, Y. Remote activation of biomolecules in deep tissues using near-infrared-to-UV upconversion nanotransducers. Proc. Natl Acad. Sci. USA 109, 8483-8488 (2012).

20. Hong, G. et al. Multifunctional in vivo vascular imaging using near-infrared II fluorescence. Nat. Med. 18, 1841-1846 (2012).

21. Jenal, U. \& Malone, J. Mechanisms of cyclic-di-GMP signaling in bacteria. Annu. Rev. Genet. 40, 385-407 (2006).

22. Tarutina, M., Ryjenkov, D. A. \& Gomelsky, M. An unorthodox bacteriophytochrome from Rhodobacter sphaeroides involved in turnover of the second messenger c-di-GMP. J. Biol. Chem. 281, 34751-34758 (2006). 
23. Burdette, D. L. et al. STING is a direct innate immune sensor of cyclic di-GMP. Nature 478, 515-518 (2011).

24. Sun, L., Wu, J., Du, F., Chen, X. \& Chen, Z. J. Cyclic GMP-AMP synthase is a cytosolic DNA sensor that activates the type I interferon pathway. Science 339, 786-791 (2013).

25. Burdette, D. L. \& Vance, R. E. STING and the innate immune response to nucleic acids in the cytosol. Nat. Immunol. 14, 19-26 (2013).

26. Barker, J. R. et al. STING-dependent recognition of cyclic di-AMP mediates type I interferon responses during Chlamydia trachomatis infection. MBio 4, e00018-13 (2013).

27. Yin, Q. et al. Cyclic di-GMP sensing via the innate immune signaling protein STING. Mol. Cell 46, 735-745 (2012).

28. Escalante, C. R., Nistal-Villan, E., Shen, L., Garcia-Sastre, A. \& Aggarwal, A. K. Structure of IRF- 3 bound to the PRDIII-I regulatory element of the human interferon-beta enhancer. Mol. Cell 26, 703-716 (2007).

29. Wurm, F. M. Production of recombinant protein therapeutics in cultivated mammalian cells. Nat. Biotechnol. 22, 1393-1398 (2004).

30. Heinrich, H., Gevensleben, H. \& Strehl, U. Annotation: neurofeedback - train your brain to train behaviour. J. Child Psychol. Psychiatry 48, 3-16 (2007).

31. Chow, B. Y. et al. High-performance genetically targetable optical neural silencing by light-driven proton pumps. Nature 463, 98-102 (2010).

32. Bruegmann, T. et al. Optogenetic control of heart muscle in vitro and in vivo. Nat. Methods 7, 897-900 (2010).

33. Kraus, T. A., Lau, J. F., Parisien, J. P. \& Horvath, C. M. A hybrid IRF9-STAT2 protein recapitulates interferon-stimulated gene expression and antiviral response. J. Biol. Chem. 278, 13033-13038 (2003).

34. Williams, N. R. \& Okun, M. S. Deep brain stimulation (DBS) at the interface of neurology and psychiatry. J. Clin. Invest. 123, 4546-4556 (2013).

35. Lenarz, T., Pau, H. W. \& Paasche, G. Cochlear implants. Curr. Pharm. Biotechnol. 14, 112-123 (2013).

36. Ricotti, L., Assaf, T., Dario, P. \& Menciassi, A. Wearable and implantable pancreas substitutes. J. Artif. Organs 16, 9-22 (2013).

37. Fernandes, R. A., Diniz, B., Ribeiro, R. \& Humayun, M. Artificial vision through neuronal stimulation. Neurosci. Lett. 519, 122-128 (2012).

38. Truini, A., Garcia-Larrea, L. \& Cruccu, G. Reappraising neuropathic pain in humans-how symptoms help disclose mechanisms. Nat. Rev. Neurol. 9, 572-582 (2013)

39. Thuret, S., Moon, L. D. \& Gage, F. H. Therapeutic interventions after spinal cord injury. Nat. Rev. Neurosci. 7, 628-643 (2006).

40. Cook, M. J. et al. Prediction of seizure likelihood with a long-term, implanted seizure advisory system in patients with drug-resistant epilepsy: a first-in-man study. Lancet Neurol. 12, 563-571 (2013).

41. Fisher, R. S. Therapeutic devices for epilepsy. Ann. Neurol. 71, 157-168 (2012).

42. Sullivan, P. F., Daly, M. J. \& O’Donovan, M. Genetic architectures of psychiatric disorders: the emerging picture and its implications. Nat. Rev. Genet. 13, 537-551 (2012)

43. Simonsen, J. L. et al. Telomerase expression extends the proliferative life-span and maintains the osteogenic potential of human bone marrow stromal cells. Nat. Biotechnol. 20, 592-596 (2002).

44. Reiser, J. et al. Transduction of nondividing cells using pseudotyped defective high-titer HIV type 1 particles. Proc. Natl Acad. Sci. USA 93, 15266-15271 (1996).

45. Mochizuki, H., Schwartz, J. P., Tanaka, K., Brady, R. O. \& Reiser, J. High-titer human immunodeficiency virus type 1-based vector systems for gene delivery into nondividing cells. J. Virol. 72, 8873-8883 (1998).

46. Link, N. et al. Therapeutic protein transduction of mammalian cells and mice by nucleic acid-free lentiviral nanoparticles. Nucleic Acids Res. 34, e16 (2006).

47. Mitta, B., Weber, C. C. \& Fussenegger, M. In vivo transduction of HIV-1derived lentiviral particles engineered for macrolide-adjustable transgene expression. J. Gene Med. 7, 1400-1408 (2005).

48. Schlatter, S., Rimann, M., Kelm, J. \& Fussenegger, M. SAMY, a novel mammalian reporter gene derived from Bacillus stearothermophilus alpha-amylase. Gene 282, 19-31 (2002).
49. Christen, M. et al. Asymmetrical distribution of the second messenger c-di-GMP upon bacterial cell division. Science 328, 1295-1297 (2010).

50. Filonov, G. S. et al. Bright and stable near-infrared fluorescent protein for in vivo imaging. Nat. Biotechnol. 29, 757-761 (2011).

51. Ryu, M. H. et al. Engineering adenylate cyclases regulated by near-infrared window light. Proc. Natl Acad. Sci. USA 111, 10167-10172 (2014).

52. Gasser, C. et al. Engineering of a red-light-activated human cAMP/cGMPspecific phosphodiesterase. Proc. Natl Acad. Sci. USA 111, 8803-8808 (2014).

53. Ekandem, J. I., Davis, T. A., Alvarez, I., James, M. T. \& Gilbert, J. E. Evaluating the ergonomics of BCI devices for research and experimentation. Ergonomics 55, 592-598 (2012).

54. Luo, A. \& Sullivan, T. J. A user-friendly SSVEP-based brain-computer interface using a time-domain classifier. J. Neural. Eng. 7, 26010 (2010).

55. Crowley, K., Sliney, A., Pitt, I. \& Murphy, D. in 2010 IEEE 10th Int. Conf. Advanced Learning Technologies 276-278 (IEEE, 2010).

56. Johnstone, S. J., Blackman, R. \& Bruggemann, J. M. EEG from a single-channel dry-sensor recording device. Clin. EEG Neurosci. 43, 112-120 (2012).

57. Szibbo, D., Luo, A. \& Sullivan, T. J. Removal of blink artifacts in single channel EEG. Conf. Proc. IEEE Eng Med. Biol. Soc. 2012, 3511-3514 (2012).

\section{Acknowledgements}

We thank Christian Zschokke and Giovanni Nisato at the Centre Suisse d'Electronique et Microtechnique (CSEM) for generous advice, Mark Gomelsky for providing the DGCL sequence before publication, Volkhard Kaever for providing the c-di-GMP HPLC/MS analysis, Patrice Del Carmine for assistance with the mouse experiments, Jörge Rothe for assistance with BCI programming and Elmar Hullinger for BCI control. This work was supported by a European Research Council (ERC) advanced grant (No. 321381) and in part by the Cantons of Basel and the Swiss Confederation within the INTERREG IV A.20 tri-national research programme.

\section{Author contributions}

M.Fo. and M.F. designed the project, analysed the results and wrote the manuscript. M.Fo., S.O., K.Z., T.T., J.H. and M.C. performed the experimental work and analysed the results. M.D.E.-B. performed the mouse work. M.Fo. and P.B. designed, constructed and assembled the electronic components.

\section{Additional information}

Accession codes: Sequence information of key components is available at GenBank: human codon-optimized DGCACC3285, GenBank ID: KM591193; human codonoptimized PDEyahA, GenBank ID: KM591194; human codon-optimized PDETBD1265, GenBank ID: KM591195; human codon-optimized DGCL, GenBank ID: KM591196; PhIFN $_{\text {hIFN }}$, GenBank ID: KM591197; PIFN(AC + ), GenBank ID: KM591198; $\operatorname{PIFN}(\mathrm{AC}+)$

Supplementary Information accompanies this paper at http://www.nature.com/ naturecommunications

Competing financial interests: The authors declare no competing financial interests.

Reprints and permission information is available online at http://npg.nature.com/ reprintsandpermissions/

How to cite this article: Folcher, M. et al. Mind-controlled transgene expression by a wireless-powered optogenetic designer cell implant. Nat. Commun. 5:5392 doi: 10.1038/ncomms6392 (2014).

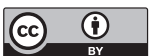

This work is licensed under a Creative Commons Attribution 4.0 International License. The images or other third party material in this article are included in the article's Creative Commons license, unless indicated otherwise in the credit line; if the material is not included under the Creative Commons license, users will need to obtain permission from the license holder to reproduce the material. To view a copy of this license, visit http://creativecommons.org/licenses/by/4.0/ 